\title{
Clinical perspectives to improve pregnancy outcome in women undergoing chronic hemodialysis
}

\author{
Luiz Paulo José Marques ${ }^{1}$, Regina Rocco², Paulo Roberto Silva Marinho², Eugênio Pacelle Queiroz Madeira ${ }^{1}$, Lygia Maria Soares Fernandes Vieira ${ }^{1}$ \\ ${ }^{1}$ Renal Unit of Gaffrèe and Guinle University Hospital-Department of Medicine, Federal University of Rio de Janeiro State, Rio de Janeiro, Brazil \\ 2 Obstetric Unit of Gaffrèe and Guinle University Hospital-Department of Medicine, Federal University of Rio de Janeiro State, Rio de Janeiro, Brazil
}

\section{ABSTRACT}

Severe Chronic Kidney Disease is considered a powerful method of contraception per se, and pregnancy among women undergoing chronic hemodialysis is a rare event. Women on dialysis usually have amenorrhea or irregular menstrual cycles and sexual dysfunction. They are often unaware of their pregnancy, which delays the diagnosis and the beginning of adequate obstetric-nephrological care, increasing the risk of maternal and fetal complications including pre-eclampsia, fetal growth restriction, preterm delivery, and perinatal death. However, pregnancy among women on dialysis is increasing exponentially around the world. The authors present the two last pregnancies of patients on dialysis followed in their hospital, review clinical procedures, and the improvements of medical care during gestation used to contribute to a successful gestation outcome. Pregnancy is possible in women on chronic hemodialysis.

Keywords: pregnancy, chronic kidney disease, hemodialysis, medical care, maternal-fetal outcome.

\section{INTRODUCTION}

Kidney Disease is associated with the highest rate of adverse maternal-fetal outcomes than any other pre-existing medical condition $^{1}$. Chronic Kidney Disease (CKD) affects up to $6 \%$ of women of childbearing age in high-income countries and is estimated to affect $3 \%$ of pregnant women. In advanced CKD, pregnancy may precipitate the need for dialysis ${ }^{2}$. Reproductive health in women with CKD is very complex, influenced by the effects of kidney disease and drug therapy used $^{3}$. CKD reduces fertility due to many factors, such as the progressive dysfunction of the hypothalamic-pituitary-gonadal axis and the decrease of renal clearance of prolactin, leading to anovulation ${ }^{4}$, and as CKD worsens, so does fertility ${ }^{5}$.

The global prevalence of CKD requiring dialysis therapy continues to increase around the world, and hemodialysis (HD) is one of the most frequent renal replacement therapies ${ }^{6}$. The association of CKD and chronic HD (defined when the patient is undergoing HD for more than 90 days while waiting for the possibility of kidney transplantation) is considered per se as a powerful method of contraception, and pregnancy in these women is described as a rare event.

However, pregnancy reports in hemodialyzed women are growing exponentially worldwide, increasing from 90 between 2000 and 2008 to 464 pregnancies between 2009 and 2014. It represents an approximate 7 -fold rise ${ }^{7}$ associated with an enhanced frequency of live births $(40-86 \%)^{8}$, mainly due to the significant progress that has been made in the obstetric-nephrological care of pregnant dialysis patients.
We reviewed the last two pregnancies and fetal outcomes of women undergoing chronic HD followed at our hospital and described clinical interventions that can contribute to a successful pregnancy.

\section{CASE REPORTS}

We reviewed the clinical management and fetal outcome of the two last pregnancies, in which obstetric-nephrological care was adjusted to our hospital clinical protocol (Table1). The patients have given their informed consent to this publication, and the local Ethical Committee approved this study.

\section{Patient 1}

A 22- year-old woman, undergoing HD for five years due to ESRD secondary to systemic lupus erythematosus, with no other comorbidity, was referred to the obstetric unit of our hospital in the $24^{\text {th }}$ week of gestation after premature parturition treated by tocolysis with salbutamol associated with dexamethasone. Pregnancy was diagnosed at $17^{\text {th }}$ week; she started obstetric care at $19^{\text {th }}$ week, and in the $20^{\text {th }}$ week, our multidisciplinary team was asked to become part of her pregnancy management. As the patient lived far from our hospital, dialysis therapy was adjusted to our hemodialysis protocol (Table 1) in her dialysis clinic.

At admission, physical examination revealed blood pressure of $130 \times 80 \mathrm{mmHg}, \mathrm{BMI}=23.8 \mathrm{~kg} / \mathrm{m}^{2}$ and no other alterations. The laboratory tests showed Hb:7.7g/dL, Hct:24.4\%, phosphorus:4.4mg/dL, urea:123mg/ 


\section{Table1}

Gaffrée Guinle University Hospital clinical protocol for pregnant women undergoing hemodialysis.

I) Clinical Care

\begin{tabular}{l} 
A) Before conception \\
\hline - Contraception counseling for women of childbearing age at the start of renal \\
replacement therapy
\end{tabular}

nancy outcomes.

\begin{tabular}{|c|}
\hline \\
\hline $\begin{array}{l}\text { 1. Diet, vitamin and mineral supplementation } \\
\text { - Protein } 1.8 \mathrm{~g} / \mathrm{kg} \text { and calories } 25-35 \mathrm{kcal} / \mathrm{kg} / \mathrm{day} \text { intake } \\
\text { - Water-soluble vitamin supplementation } \\
\text { - Folic acid } 1-5 \mathrm{mg} \text { daily } \\
\text { - Calcium } 1.0-1.5 \mathrm{~g} \text { daily } \\
\text { - Calcium chelating agents and vitamin } \mathrm{D} \text { analogs if necessary. } \\
\text { - Phosphate supplementation if necessary }\end{array}$ \\
\hline $\begin{array}{l}\text { 2. Anemia } \\
\text { - Adequate intravenous iron sucrose dose and erythropoietin (double to triple the } \\
\text { pre-pregnancy dose) } \\
\text { - Target hemoglobin at } 10-12 \mathrm{~g} / \mathrm{dL} \text {, serum ferritin }>300 \mu \mathrm{gg} / \mathrm{mL} \text { and transferrin satu- } \\
\text { ration }>30 \%\end{array}$ \\
\hline $\begin{array}{l}\text { 3. Blood pressure control } \\
\text { - Maintain blood pressure } \leq 140 \text { / } 90 \mathrm{mmHg} \text { pre and post hemodialysis } \\
\text { - Drugs to use during pregnancy: } \alpha \text {-methyldopa, long-acting nifedipine, amlodipine, } \\
\text { verapamil, hydralazine, and labetalol. }\end{array}$ \\
\hline $\begin{array}{l}\text { 4. Intensive Hemodialysis (HD) Prescription } \\
\text { - Six sessions (Monday to Saturday) / week, with 4-5 hours / session } \\
\text { - Use high biocompatible dialysis membranes. } \\
\text { - Heparin: the same pre-pregnancy dose } \\
\text { - Blood flow: } 200-300 \mathrm{~mL} / \mathrm{min} \\
\text { - Dialysate flow: } 500 \mathrm{~mL} / \mathrm{min} \\
\text { - Perform biweekly lab examinations } \\
\text { - Maintain near-normal urea (20-50 mg/dL) pre-dialysis during pregnancy }\end{array}$ \\
\hline $\begin{array}{l}\text { 4a. Ultrafiltration (UF) } \\
\text { - Reassess and set dry weight weekly on the } 1 \mathrm{st} \mathrm{HD} \text { session of the week, after the } \\
\text { daybreak } \\
\text { - Increase in maternal dry weight of } 1-1.5 \mathrm{~kg} / \text { quarter in the first quarters } \\
\text { - Increased maternal dry weight: } \pm 0.5 \mathrm{~kg} / \text { week from the } 24 \text { th week of gestation } \\
\text { - Preferably perform HD without ultrafiltration to avoid hemodynamic instability } \\
\text { and intradialytic arterial hypotension (Blood pressure }<120 / 70 \mathrm{mmHg} \text { ) } \\
\text { - When UF is required, it should be done at a rate of UF }<6 \mathrm{~mL} / \mathrm{kg} / \mathrm{hour} \text {. } \\
\text { - Increase HD session time to five hours whenever the prescribed ultrafiltration rate } \\
\text { is } \geq 2000 \mathrm{~mL}\end{array}$ \\
\hline $\begin{array}{l}\text { 4b. Adapt Dialysate: } \\
\text { - Potassium levels: } 3 \mathrm{mEq} / \mathrm{L} \\
\text { - Bicarbonate: } 25 \mathrm{mEq} / \mathrm{L} \\
\text { - Calcium: } 1.5 \mathrm{mmol} / \mathrm{L}\end{array}$ \\
\hline $\begin{array}{l}\text { 5. Obstetric care } \\
\text { - Ultrasound to diagnose pregnancy } \\
\text { - Monthly obstetric consultation and ultrasound } \\
\text { - Ultrasound in weeks } 11 \text { through } 13 \text { to measure the cervical length and assess for } \\
\text { - Uetal anomalies } \\
\text { - Ultrasound with morphologic biophysical profile and placental ultrasound with } \\
\text { - Boppler assessment in the } 22^{\text {nd }} \text { week } \\
\text { vide close follow-up of placental function, fetal growth, and amniotic fluid volume. }\end{array}$ \\
\hline
\end{tabular}

$\mathrm{dL}$, creatinine:7.5mg/dL, albumin:3.0mg/dL, potassium:4.3mEq/L, sodium:136mEq/L, calcium:7.8mg/dL and intact PTH:282pg/mL.

At the end of the first HD session in our hospital, without any circulatory stress or hypotension during $\mathrm{HD}$, she complained of abdominal pain and had a premature boy by spontaneous vaginal delivery (weight 570g, height $31 \mathrm{~cm}$, and Apgar score=2). The baby was resuscitated and taken to the neonatal ICU with a hyaline membrane, where he stayed for 96 days. He had a good clinical recuperation and was discharged after 126 days of hospitalization.

\section{Patient 2}

A 33-year-old woman, undergoing HD for three years due to ESRD secondary to focal segmental glomerulosclerosis, with no other comorbidity, complained of abdominal volume increase. Pregnancy was diagnosed in the $12^{\text {th }}$ week of gestation and the dialysis schedule adjusted by our multidisciplinary team. She was referred to obstetric care and began HD treatment in our hospital in the $16^{\text {th }}$ week.

Physical examination at admission revealed blood pressure of $120 \times 80 \mathrm{mmHg}, \mathrm{BMI}=27.8 \mathrm{~kg} / \mathrm{m}^{2}$ and $+/ 4+$ leg edema. There were no other physical signs. The laboratory tests showed $\mathrm{Hb}: 9.5 \mathrm{~g} / \mathrm{dL}, \mathrm{Hct}: 29.6 \%$, creatinine clearance: $3.8 \mathrm{ml} / \mathrm{min} / 1,73 \mathrm{~m}^{2}$, proteinuria: $160 \mathrm{mg} / 24 \mathrm{hours}$, glucose: $96 \mathrm{mg} / \mathrm{dL}$, urea:138 $\mathrm{mg} / \mathrm{dL}$, albumin: $3.4 \mathrm{mg} / \mathrm{dL}$, potassium:5.2mEq/L, sodium:138mEq/L, calcium: $8.1 \mathrm{mg} / \mathrm{dL}$, phosphorus: $4.5 \mathrm{mg} / \mathrm{dL}$ and intact PTH:282pg/mL. Diet, water-soluble vitamins, folic acid, calcium chelating agents, and intravenous iron sucrose dose were adjusted to our clinical protocol. Erythropoietin went to double the pre-pregnancy dose and 25 hydroxyvitamin D dose was increased to $10.000 \mathrm{Ul} /$ week.

She performed $122 \mathrm{HD}$ sessions with a low UF rate $(2-5 \mathrm{~mL} / \mathrm{h} / \mathrm{kg})$ in our service. UF was necessary due to the interdialytic weight gain $0.5-2.9 \mathrm{~kg}(1.76 \pm 0.5 \mathrm{~kg})$, and her total weight gain was $10.8 \mathrm{~kg}$ during gestation. The pre-dialysis urea following the HD day break ranged from 62 to $94(75.9 \pm 8.9) \mathrm{mg} / \mathrm{dL}$ during the pregnancy. She had a healthy boy by spontaneous vaginal delivery at 37th week \pm 4 days of gestation, and the fetal growth matched his gestational age (weight $=2595 \mathrm{~g}$ and height $=47 \mathrm{~cm}$ with APGAR score=9). After pregnancy, her dry weight increased by up to $2.5 \mathrm{~kg}$.

\section{DISCUSSION}

Pregnancy in patients undergoing chronic HD is one of the highestrisk pregnancies, associated with poor outcome and a high incidence of maternal-fetal complications. Two factors are critical to successful pregnancy: 1) Pre-conception counseling, given together by obstetricians-gynecologists and nephrologists is essential to support the woman and her partner in making an informed decision about planned pregnancy, offers an opportunity to avoid teratogenic medication, to control potential adverse events, and allows early pregnancy diagnosis $^{9}$, and 2) Intensive adequate dialysis with the widespread use of biocompatible membranes, increasing dialysis session number and dialysis dose greater than 21 hours of HD per week, associated with erythropoiesis-stimulating agents ${ }^{10}$.

It has been demonstrated that pregnancy in women undergoing chronic HD is increasing; $50 \%$ of them are sexually active, and half of these gestations occur within the first year of starting dialysis ${ }^{11}$. However, less than half of nephrologists counsel their female dialysis patients of childbearing age about contraception and pregnancy. 
Unplanned pregnancy in these women is associated with a high rate of adverse maternal-fetal outcomes ${ }^{12}$.

In our hospital, all women of childbearing age receive regular detailed counseling regarding contraception options and pregnancy at the start of renal replacement therapy, to avoid unplanned pregnancy. They are also referred to the gynecology outpatient clinic for follow-up. Deferring pregnancy until a renal transplant is achieved is the ideal option, although complications remain high ${ }^{13}$. However, given prolonged waiting times for organs, the reproductive years may have passed. Thus, when a woman intends to get pregnant, the couple receives preconception counseling by a collaborative multidisciplinary team in the Nephro-Obstetric outpatient clinic. Accurate and carefully detailed information about the maternal-fetal risks and pregnancy outcomes are given, to support the couple in making an informed decision about pregnancy.

However, these two women did not receive any medical orientation and had unplanned pregnancies. In one of them, the diagnosis was late, which delayed obstetric-nephrological care, resulted in a very premature fetus delivered with severe medical complications, and the baby was hospitalized for 126 days. A planned pregnancy is critical to begin obstetric-nephrological care, adjust dialysis, make an early diagnosis, and avoid gestational complications. Since most of the women receiving HD have menstrual irregularities, infertility, and sexual dysfunction ${ }^{5}$, they are often unaware of their pregnancy, which delays the diagnosis in an unplanned pregnancy.

There are several potential mechanisms wherein the intensive dialysis regimen may contribute to improved pregnancy outcomes, such as better control of uremia, anemia, blood pressure, and interdialytic weight gains, as well as increase endothelial function and decrease inflammation ${ }^{14}$. However, the result obtained in these dialysis regimens appears to be directly related to enhancing urea clearance. There is an inverse association between BUN level and live birth rate, birth weight, and gestational age, with more favorable fetal outcomes when the serum urea level is near normal ${ }^{15}$.

In our hospital, the HD time is increased to 24-30 hour/week with six sessions/week (Table 1), whereas increasing the time and the number of HD sessions improves infant survival ${ }^{10}$. HD is performed with standard heparin anticoagulation to offer proper dialysis using high biocompatibility dialyzer with less filtration area to provide lower ultrafiltration (UF) fluid loss and high efficiency (Kt/v from 1.5-1.7, recommended $\mathrm{Kt} / \mathrm{v}>1.2$ ) and individualized $U F^{16}$.

The UF method used to remove the fluid excess and prevent the deleterious effect of hypervolemia must be performed cautiously during pregnancy to avoid hypotension, circulatory stress, and placental ischemia. It is difficult to determine the dry weight and assure that the pregnant woman on dialysis is euvolemic. The expected weight gain in the first trimesters is minimal $(0.5-1.5 \mathrm{Kg} /$ trimester). From the 24 th week of gestation, the weight gain recommended is up to $0.5 \mathrm{~kg} /$ week, and dry weight must be re-evaluated and defined in all first dialysis of the week ${ }^{15}$. The goal to perform HD in pregnant women without UF for fluid removal is admirable but difficult to obtain since most weight gain in the interdialytic period is fluid. During pregnancy, the UF rate must be
$<6 \mathrm{~mL} / \mathrm{h} / \mathrm{kg}$ to minimize placental circulatory alterations and deleterious fetal effects ${ }^{16,17}$.

In medical care, diet must be adequate for both maternal and fetal daily requirements, with $1.8 \mathrm{~g}$ protein and $35 \mathrm{Kcal} / \mathrm{kg} /$ day, supplementation of vitamins, minerals, folic acid, calcium-based binders, and vitamin $D$ analogs when necessary, and associated with intravenous iron sucrose and double or triple the usual doses of erythropoietin to treat anemia (Table1). In the HD prescription, the dialysate is adapted to potassium levels of $3-3.5 \mathrm{mmol} / \mathrm{L}$, the calcium of $1.5 \mathrm{mmol} / \mathrm{L}$, and bicarbonate concentration of $25 \mathrm{mEq} / \mathrm{L}$ to avoid electrolytes disorders and alkalosis ${ }^{16}$.

In our hospital, the pregnant patient is followed up by a collaborative multidisciplinary team that includes nephrologists, obstetricians, and support staff (nutritionist, nurse, psychologist, physiotherapist, and social worker). The careful obstetric surveillance included monthly consultation and Doppler ultrasonography until the 24th week and after, weekly or biweekly until delivery, to provide information about placental status, fetal growth, amniotic fluid volume, maternal-fetal well being and to determine the timing of delivery. The women on dialysis should be encouraged to breastfeed and to see motherhood as a healthy event. However, some cautions should be observed with the mother's medications used, and aggressive UF may decrease milk production.

Ideally, the hospital that will provide care of pregnant women with renal diseases must have neonatal intensive care, renal and obstetric units, associated to an experienced, collaborative multidisciplinary team, that include nephrologists, obstetricians who specialize in highrisk pregnancy, and nephrology support staff (dieticians, nurses, and others), with regular team meetings and accessible communication to review strategies. These patients must have specialized care in the Nephro-Obstetric outpatient clinic during pregnancy ${ }^{18}$. However, women who live far should be managed collaboratively with this kind of experienced team.

CONCLUSION: Pregnancy is possible in women undergoing chronic $\mathrm{HD}$, and the obstetricians-gynecologists and nephrologists must include discussion about contraception methods and pregnancy in clinical practice for women of childbearing age at the start of renal replacement therapy, to offering an opportunity to avoid teratogenic medication, to control potential adverse events and allow early pregnancy diagnosis. Early diagnosis of a planned pregnancy associated with individualized intensive HD and adequate obstetric care is crucial to increase gestation success.

\section{Disclosure of potential conflicts of interest: none declared}

\section{References}

1. Kendrick J, Sharma S, Holmen J, Palit S, Nuccio E, Chonchol M. Kidney disease and maternal and fetal outcomes in pregnancy. Am J Kidney Dis. 2015 July;66(1):55-59.

2. Webster P, Lightstone L, McKay DB, Josephson MA. Pregnancy in chronic kidney disease and kidney transplantation. Kidney Int. 2017; 91:1047-1056.

3. Burgne A, Hladunewich MA. Women's reproductive health for the nephrologist. Am J Kidney Dis. 2019;74:675-681.

4. Dumanski SM, Ahmed SB. Fertility and reproductive care in chronic kidney disease. J Nephrol. 2019;32(1):39-50.

5. Wiles KS, Nelson-Piercy C, Bramham K. Reproductive health and pregnancy in women with chronic kidney disease. Nat Rev Nephrol. 2018;14(3):165-184. 
6. Lv JC, Zhang LX. Prevalence and disease burden of chronic kidney disease. Adv Exp Med Biol. 2019;1165:3-15.

7. Piccoli GB, Minelli F, Versino $E$ et al. Pregnancy in dialysis patients in the new millennium: a systematic review and meta-regression analysis correlating dialysis schedules and pregnancy out comes. Nephrol Dial Transplant. 2016;31:1915-1934.

8. Piccoli GB, Cabiddu G, Daidone $G$ et al. The children of dialysis: live-born babies from on-dialysis mothers in Italy -an epidemiological perspective comparing dialysis, kidney transplantation and the overall population. Nephrol Dial Transplant. 2014;29:1578-1586.

9. Wiles KS, Bramham K, Vais A et al. Pre-pregnancy counselling for women with chronic kidney disease: a retrospective analysis of nine years' experience. BMC Nephrology. 2015;16:28-33.

10. Hladunewich MA, Hou S, Odutayo A. Intensive hemodialysis associates with improved pregnancy outcomes: a Canadian and United States cohort comparison. J Am Soc Nephrol. 2014; 25:11031109.

11. Holley JL, Reddy SS. Pregnancy in dialysis patients: a review of outcomes, complications, and management. Semin Dial. 2003;16:384-388.

12. Sachdeva M, Barta B, Thakkar J et al. Pregnancy outcomes in women on hemodialysis: a national survey. Clin Kidney J. 2017;10:276-282.

13. Piccoli GB, Cabiddu G, Attini R et al. Pregnancy outcomes after kidney graft in Italy: are the changes over time the result of different therapies or of different policies? A nationwide survey (1978-2013). Nephrol Dial Transplant. 2016;31:1957-1965.
14. Hladunewich MA, Schatell D. Intensive dialysis and pregnancy. Hemodialysis Int. 2016;20:339-334. 15. Asamiya $Y$, Otsubo $S$, Matsuda $Y$ et al. The importance of low blood urea nitrogen levels in pregnant patients undergoing hemodialysis to optimize birth weight and gestational age. Kidney Int 2009;75:1217-1222.

16. Marques LPJ, Marinho PRS, Rocco R, et al. Effect of ultrafiltration on placental-fetal blood flow in pregnancy of woman undergoing chronic hemodialysis. Hemodialysis Int. 2018;22:405-412.

17. Marques LPJ. Pregnancy among women undergoing chronic hemodialysis: effect of ultrafiltration during gestation. J Clin Nephrol Ther. 2018;2(1):11-12.

18. Nogueira E, Rita Calça R, Godinho I, Pinto L. Nephro-Obstetric outpatient clinic model. Port J Nephrol Hypert. 2020;34:3-10.

\section{Correspondence to:}

Luiz Paulo José Marques

Hospital Universitário Gaffrée Guinle / Universidade Federal do Estado do Rio de Janeiro

Rua Conde de Bonfim, 370/502;Tijuca - 20520 - 054 Rio de Janeiro- RJ. E-mail: marqueslpj2016@gmail.com 